\title{
Product familiarisation programs
}

\section{Greg Kyle}

Professor of Pharmacy

Director International

Engagement and

Recruitment

School of Clinical Sciences Queensland University of Technology

Brisbane

\section{Keywords}

dabigatran, drug promotion, medicine access programs, Pharmaceutical Benefits Scheme

Aust Prescr 2017;40:206-7 https://doi.org/10.18773/ austprescr.2017.076
Product familiarisation programs (sometimes also called 'patient familiarisation programs') are provided by pharmaceutical companies and are designed to familiarise prescribers with a newly approved medicine while Pharmaceutical Benefits Scheme (PBS) listing is pending. ${ }^{1}$ They are usually targeted at specialists and, according to Medicine Australia's Code of Conduct, each individual prescriber can only enrol up to ten patients in a program. The enrolment period is limited to six months, however extensions are allowed if there is a strong clinical or equity rationale. ${ }^{2}$

Probably the biggest product familiarisation program in Australia was conducted by Boehringer Ingelheim for the anticoagulant dabigatran (Pradaxa). Specialists and GPs were approached starting from June 2011 and around 25000 patients were enrolled in total. ${ }^{3}$ The program was extended from June 2012 to December 2013 because the Government delayed PBS listing to review a report on anticoagulant therapies. ${ }^{4}$

Supporters of these programs argue that they increase patient access to medicines and assist with the affordability of new medicines. Prescribers can gain experience with a new drug in 'real world' patients at no financial risk to the patient. Such use allows specialists and GPs to test and monitor patients enrolled in the program, thereby increasing their experience with the new drug and enabling earlier reporting of any adverse drug reactions in 'real world' as opposed to clinical trial patients.

Another advantage is cost. Because the drug's sponsor bears the cost of the product supplied during the program, treatment is free for the patient. This also represents a significant saving to the Government. When listed on the PBS for non-valvular atrial fibrillation on 1 September 2013, the dispensed price for the maximum quantity of dabigatran $110 \mathrm{mg}$ or $150 \mathrm{mg}$ was $\$ 96.12$. Using this (imperfect) measure for simplicity, the dispensed-price cost would have been $\$ 2403000$ per month for 25000 patients.

Opponents of product familiarisation programs argue that they are thinly disguised marketing exercises that could increase the net cost of the PBS to the Australian Government. Pharmaceutical companies could use them to gain early exposure to prescribers with their newest drug.

Sponsors will report the headline cost to demonstrate their generosity. However, the dispensed price does not represent the true cost of the drug to the sponsor. While the Government does save money when the product familiarisation program is running, it can be argued that the sponsor is building a ready supply of patients once PBS listing is achieved. In the dabigatran case, there were approximately 25000 patients ready to continue their prescription on the PBS.

There is also a societal cost to consider, especially with a paucity of head-to-head clinical trials between any new drug and existing therapy. The short-term effect of a familiarisation program may save the Government money, but what is the long-term impact? If the new drug has only marginal incremental patient benefit, but with greater cost, it can sequester PBS money that could have been used for a different drug with a larger incremental benefit.

The big question on most practitioners' minds will probably be 'should I participate or not?' However, it is important to recognise the marketing aspect of these programs that will not be mentioned by company representatives. The overarching aim of sponsors is to sell their drugs.

The decision to enrol a patient in a program should be based on what is best for them. Often newer drugs will not have large amounts of postmarketing experience of their use, and familiarisation programs can provide some experience. It may also be difficult to obtain independent information about the new drug and determine its place in therapy to make an evidence-based prescribing decision. All these factors need to be considered in the decision making.

This is another of the vexed issues in medicine - there are patient benefits, but there is also no such thing as a free lunch ... for prescribers or for patients. $\varangle$

Conflict of interest: none declared 


\section{REFERENCES}

1. Council of Australian Therapeutic Advisory Groups Managing Medicines Access Programs: guiding principles for the governance of Medicines Access Programs in Australian hospitals. Sydney: CATAG; 2015. http://www.catag.org.au [cited 2017 Nov 1]

2. Medicines Australia. Code of Conduct. 18th ed https://medicinesaustralia.com.au/code-of-conduct/ code-of-conduct-current-edition [cited 2017 Nov 1]
3. Drug Utilisation Sub-Committee. Novel oral anticoagulants: predicted vs actual analysis. Public Release Document, June 2016 DUSC Meeting, Canberra. http://www.pbs.gov.au/info/ industry/listing/participants/public-release-docs/noacsnon-valvular-atrial-fibrillation-june-2016 [cited 2017 Nov 1]

4. Colyer S. Free dabigatran scheme extended. Australian Doctor. 2017 April 26. www.australiandoctor.com.au/ news/latest-news/free-dabigatran-schemeextended?t=636319921112856541 [cited 2017 Nov 1]

\section{FURTHER READING}

Vitry A. How big pharma opens the market to new expensive drugs. The Conversation. 2012 June 26. http://theconversation. com/how-big-pharma-opens-the-market-to-new-expensivedrugs-7620 [cited 2017 Nov 1]
Patounas MP, McGuire TM. Starter packs: a good start to therapy? Aust Prescr 2007;30:14-6. https://doi.org/10.18773/ austprescr.2007.007 